\title{
Meteorites and the Craters on the Moon
}

\author{
By Dr. L. J. Spencer, C.B.E., F.R.S.
}

$S^{\mathrm{E}}$ EVERAL views have, from time to time, been put forward to explain the origin of the remarkable series of shallow craters on the surface of the moon. One of these is that they were formed by the impact of meteorites. Two main objections to this view have been frequently stated. It is said that all meteorites would not have fallen in a direction perpendicular to the surface to produce craters of a circular outline : many must have fallen obliquely and formed oval craters. Again, it is often asked: Why is the earth's surface not pock-marked in the same fashion? A study of meteorite craters and of meteoritic showers ${ }^{1}$ on the earth's surface shows that both these objections are without justification.

Since the discovery of the meteorite craters at Henbury in Central Australia ${ }^{2}$ in 1931 and at Wabar in Arabia $^{3}$ in 1932, it has been clearly demonstrated that these are not craters of impact or percussion, but that they are explosion craters. The kinetic energy of a large mass of iron (nickeliron) travelling at a high velocity, was suddenly transformed into heat, vaporizing a large part of the meteorite and some of the earth's crust, so producing a violent gaseous explosion, which formed the crater and back-fired the remnants of the meteorite. Such an explosion crater will be circular in outline whatever be the angle of approach of the projectile. The materials collected at the Wabar craters afford the clearest evidence that very high temperatures prevailed. The desert sand was not only melted, yielding a silicaglass, but this boiled (b.p. about $3,500^{\circ} \mathrm{C}$.) and was vaporized. The meteoritic iron was also in large part vaporized, afterwards condensing as a fine drizzle. Minute spheres of nickel-iron, of the same composition as the meteorite, are preserved in the bubbly silica-glass. In some portions these are present to the extent of about two million per cubic centimetre of the glass. The fact that these minute spheres show a bright and highly polished surface suggests that the earth's atmosphere was blown aside in the fiery blast.

On the earth's surface, only five really certain examples of meteorite craters are yet known. These are all associated with fragments of meteoritic iron. Stony meteorites have not been found around any crater, despite the fact that, of observed meteoritic falls, 95 per cent are stones. Irons form only 5 per cent of observed falls ; but they account for 82 per cent of 'finds' of which the fall is not recorded. The friable stony meteorites are usually broken up in the earth's atmosphere, and fall as a shower of stones. Only a really large mass of iron can possibly give rise to a crater. Near the largest known iron meteorite, the Hoba in South-West Africa, weighing 60 tons (or 100 tons allowing for the surrounding zone of iron-shale), there is no sign of a crater.

Astronomers, who revel in large numbers, tell us that some twenty million meteors enter the earth's atmosphere every day. The majority of these are assumed to be the size of a pea or a grain of sand. But perhaps they may be much larger, for the ablation of material from the surface of a meteor must be enormous. In any event, those that reach the earth's surface must have been very much reduced in size; and the number actually collected each year averages only five. We have to be thankful that our atmosphere extends for at least a hundred miles above the earth's surface.

On the moon, with the absence of an atmosphere, conditions are very different. Meteorites there will encounter no check on their velocity. They will not be reduced in size, and stony masses will not be broken up. They will strike the surface at 20 or 40 or more miles per second. An astronomically small body with a radius of 100 feet and consisting of nickel-iron with a density of $7 \cdot 7$ will have a mass of very nearly a million tons and a kinetic energy measured by $\frac{1}{2} m v^{2}$. When this is arrested, something is going to happen. Part of the energy will be expended in penetrating and compressing the materials on the surface of the moon. This pressure will be released with explosive violence and moonquake waves will result. But a large part of the energy will be transformed into heat, vaporizing the meteorite and adjacent materials, and causing a violent gaseous explosion.

The idea of such a gaseous explosion was anticipated before the discovery of the Henbury and Wabar craters in a remarkable paper which has only now come to my notice and which appears to have been generally overlooked. In 1924, A. C. Gifford ${ }^{4}$ compared the craters on the moon with the Arizona crater, and he concluded that they are explosion craters. The energy of a meteorite travelling at 20 miles per second he 
calculated to be 123,900 calories per gram, and at 40 miles per second to be 494,700 cal./gm.; compared with the energy of dynamite of about $1,100 \mathrm{cal} . \mathrm{gm}$. He assumed that the meteorite would penetrate to a depth of two miles in the moon's crust (but this is surely too deep), and calculations for various velocities $(0.01-0.32$ miles per second) of the ejected materials gave for the resulting craters diameters of $0 \cdot 197-202$ miles across the rim. He further showed that a central peak will be formed inside the crater, and that the amount of material ejected may be fifty or sixty thousand times the mass of the meteorite.

S. Mohorovičićs in 1928 also concluded that the lunar craters are explosion craters, but he attributed them to explosive volcanic action. By exploding charges buried in cement powder, he produced craters with a striking resemblance to those on the moon, some of which show the central peak and the outer radial streaks. Similar craters were also produced by Alfred Wegener ${ }^{6}$ by throwing spoonfuls of cement powder on to a level surface of the same material; and he concluded that the lunar craters were formed merely by the impact of meteorites. Robert Hooke in his "Micrographia" (London, 1665, p. 243) compared the craters on the moon with those formed by the "eruption of vapours" on the surface of "a pot of boyling Alabaster", and with those formed by dropping bullets on to wet "Tobacco-pipe clay". $\mathrm{He}$ rejected the analogy of impact, for, as he naively remarks, "it would be difficult to imagine whence those bodies should come." In his day, reports of the fall of stones from the sky were discredited by scientific men. These experimental craters are shallow saucer-shaped depressions with a steep inner slope at the rim and a gentle slope outside, just as is seen in meteorite craters. Larger artificial craters of the same kind are formed by high-explosive shells and military mines.

The bright streaks radiating for hundreds of miles from some moon craters, for example, Tycho and Copernicus, but casting no shadows and conspicuous only at full moon, present a difficult problem. These craters may perhaps be due to the fall of large meteoritic irons, the density of which is $7 \cdot 7$, as compared with 3.5 of stones. The vaporized metal probably condensed as millions of tiny spheres, as at Wabar. (An astronomical calculation will give the number of such spheres, $0.01 \mathrm{~mm}$. in diameter, that could be produced from, say, a million tons of metal!) The force of gravity on the moon being only one sixth of that on earth and there being no air resistance, such particles might be projected for great distances by the explosion. Experimental explosion craters show rays of material beyond the crater rim; Mohorovičić obtained rays a metre in length outside a crater $3 \cdot 6 \mathrm{~cm}$. in diameter. It may be suggested that these bright streaks on the moon are areas covered by tiny spheres of shining metal. Some support to this view is given by the fact that the ratio of the number of craters showing bright rays and spots to those without these features is of the same order as the ratio of the numbers of irons and stones that reach the earth. Craters that show no bright rays and spots can then be supposed to have been formed by the fall of stony meteorites.

The darker areas or 'seas' of the moon show fewer craters, and some of those around the borders are broken. These areas perhaps represent lava-fields of more basic lava from fissure eruptions, comparable with the plateau basalts of the Brito-Arctic region, the Columbia River in the western United States, and the Deccan in India. (The density of basalt, $2 \cdot 8-3 \cdot 1$, is less than that of the moon as a whole, 3.3.) Such areas must be of later date than the broken craters and the surrounding mountains; but earlier than the fewer perfect craters within the areas, and also earlier than the bright streaks running across them from craters outside. The mountains are no doubt the result of crustal movements following shrinkage; and are earlier than the lava-fields. The several craters evidently belong to different periods. Some were no doubt formed when the moon first had a solid crust. Except when engulfed by lava-fields, these features will persist, for, in the absence of water and an atmosphere, there can be no denudation, as takes place on the earth. The effects of insolation and desert weathering must, however, be particularly severe-a point that does not seem to have been realized. With the sudden changes in temperature from the very hot day to the very cold night, each with a duration of half a lunar month, rocks will be exfoliated and crystals cracked along their cleavages, and all materials on the surface will be reduced to a fine powder.

On the earth, the few known meteorite craters are of recent formation, though none within the historic period. The same is true of the fall of the eleven known larger masses of meteoritic iron, ranging from the Hoba of 60 tons to the Cranbourne of $3 \frac{1}{2}$ tons in the British Museum collection. These will be destroyed by weathering and all traces of them obliterated by denudation long before the next geological period. Fossil meteorites are not known; nor is there any probability of any ever being found. The argument based on the absence of pitting on the earth's surface could never have come from a geologist.

Considered as volcanoes, the lunar craters can be compared only with explosion craters. 
None of them shows a cone reaching as high as the outer rim. Further, these cones are usually craterless, and more of the nature of a central peak. In nearly all the craters the rim is complete. In the few good examples of terrestrial volcanic explosion craters, formed by the blowing away of the cone of a typical volcano, the rim is always broken. The Monte Somma rim extends only half-way round the new Vesuvius, and the rim of Krakatoa is very irregular. The quiescent type of the Hawaiian volcanoes have craters of irregular outline. Photographs of a model of Vesuvius and the volcanoes of the Phlegrean Fields have been given to show an apparent similarity to the lunar craters; but the photographs, being taken in plan, are misleading, for these volcanoes are actually cones rather than depressed craters. Terrestrial voleanoes are distributed along lines of weakness in the earth's crust; whereas the craters on the moon are scattered about promiscuously, as if from a pepper-pot.

A point that perhaps invalidates the meteorite theory is that there is no evidence of the formation of craters on the moon at the present time. An apparent variation in the size and brightness of the small crater mapped as Linné affords the only doubtful evidence of any change. Nevertheless, meteorites are still falling on the earth, in spite of the protecting atmosphere ; and presumably they must also be falling on the moon. In earlier periods it is evident that the meteoritic bombardment must have been much more intense. Maybe the larger stray masses of the solar system have already been gathered up. On the earth during historic times there has been no catastrophic fall, except perhaps that on June 30,1908 , at a spot in central Siberia, almost as inaccessible to us as the moon itself, and of which precise information is still lacking.

\footnotetext{
${ }^{1}$ Details are given in recent papers in the Mineralogical Magazine, and abstracts of recent literature in Mineralogical Abstracts.

2 NATURE, 129, 781 (1932)

s NATURE, 129, 932 (1932)

"Gifford, A. C., "The Mountains of the Moon." Nein Zealand $J$. Sci. Tech., 7, 129-142 (1924); and recapitulation in 11, 319-327 (1930). See NATURE, 126, 379 (1930).

${ }^{3}$ Mohorovicic, S., "Experimentelle Untersuchungen über die Entste-" hung der Mondkrater : ein neuer Beitrag zur Explosionshypothese." (Croatian with German summary.) Archiv za Hemiju i Farmaciju, Cagreb, 2, 66-76+4 plates (1928).

-Wegener, A., "Die Entstehung der Mondkrater." (Sammiung vieweg, Heft 55, Braunschweig, 1921).
}

\title{
Pigments Associated with the Fatty Tissues of Plants and Animals*
}

\author{
By Prof. I. M. Heilbron, F.R.S., and A. E. Gillam
}

$\mathrm{T}^{\mathrm{T}}$ URNING now to a brief consideration of the question of the biogenesis of the carotenoids, their structure reveals an obvious connexion with isoprene

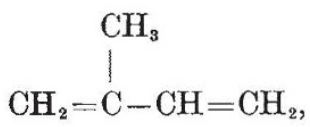

a hydrocarbon that may be regarded as the fundamental unit from which numerous important plant products are elaborated, as a result of the regular combination of individual units. The fact that the carotenoids are symmetrical necessitates, however, the assumption that they are built up in the plant, not on this simple plan alone, but by the union of two molecules of an intermediate compound containing twenty carbon atoms. According to Karrer, this may be the alcohol phytol, $\mathrm{C}_{20} \mathrm{H}_{39} \mathrm{OH}$, which constitutes approximately one third of the chlorophyll molecule. Condensation of two phytyl residues could thus theoretically give rise to lycopene from which, by simple ring closure, the carotenes would be produced.

In conclusion, the physiological importance of * Continued from p. 615. these pigments in the economy of life must be considered. So early as 1919, Steenbock advanced evidence of a possible connexion between carotene and vitamin $\mathrm{A}$, the physiologically important substance found in all liver oils, notably those of the cod and halibut. This is essential for growth, for in its absence young animals cease to grow, and ultimately die. More specific effects due to vitamin A deficiency are the eye disease, xerophthalmia, decreased resistance to respiratory infections and night-blindness. This latter affection is completely curable in a few days by the absorption of food rich in vitamin $A$; its cause appears to be related to the fact observed by Wald that the vitamin plays an essential role in the visual perception which occurs on the retina of the eye. The vitamin itself forms an almost colourless highly viscous oil which is notable for its intense absorption band at $328 \mathrm{~m} \mu$, and the characteristic blue colour which it gives with antimony trichloride. It is thus clear that the pigment carotene cannot itself be vitamin A, but, as established by von Euler in 1929, it can nevertheless replace the typical vitamin in the animal organism. Complete clarification of this apparent anomaly was reached when Moore conclusively 